\title{
Management of ADHD in children across Europe: patient demographics, physician characteristics and treatment patterns
}

\author{
Paul Hodgkins • Juliana Setyawan • Debanjali Mitra • \\ Keith Davis • Javier Quintero • Moshe Fridman • \\ Monica Shaw • Valerie Harpin
}

Received: 13 November 2012 / Accepted: 4 February 2013 /Published online: 26 February 2013

(C) The Author(s) 2013. This article is published with open access at Springerlink.com

\begin{abstract}
This study was a retrospective chart review performed to examine and describe physician practice patterns in managing attention deficit/hyperactivity disorder (ADHD) across Europe. Physicians treating ADHD in the UK, France, Germany, Italy, the Netherlands and Spain were recruited. Each physician abstracted medical records of five patients (aged 6-17 years at time of review) with a documented diagnosis of ADHD made between January 2004 and June 2007. Data provided by the physician via the abstraction included (a) physician characteristics, (b) patient characteristics, (c) ADHD diagnosis and (d) ADHD outcomes (adherence, symptom control and satisfaction). A
\end{abstract}

P. Hodgkins $(\varangle) \cdot J$. Setyawan

Shire Development, LLC,

725 Chesterbrook Boulevard,

Wayne, PA 19087, USA

e-mail: phodgkins@shire.com

D. Mitra $\cdot$ K. Davis

RTI Health Solutions,

Research Triangle Park, NC, USA

J. Quintero

Hospital Universitario Infanta Leonor,

Madrid, Spain

M. Fridman

AMF Consulting, Inc,

Los Angeles, CA, USA

\section{Shaw}

Norgine Pharmaceuticals,

Uxbridge, Middlesex, UK

V. Harpin

Ryegate Children's Centre,

Sheffield, South Yorkshire, UK total of 779 patients met study inclusion criteria. In the overall population, patients' mean (SD) age at time of diagnosis was 8.9 (2.6) years. The predominant treatment choice was long-acting methylphenidate, which was prescribed to more than $56 \%$ of patients. According to physicians, only $30.8 \%$ of patients showed 'complete symptom control' on current treatment and only $31.8 \%$ of physicians reported being 'very satisfied' with their patients' current treatment. Physicians' assessments of complete symptom control and physician satisfaction with treatment were low, indicating unmet needs with current ADHD management in Europe.

Keywords Attention deficit/hyperactivity disorder . Methylphenidate $\cdot$ Amphetamine $\cdot$ Atomoxetine

\begin{tabular}{|c|c|}
\hline \multicolumn{2}{|l|}{ Abbreviations } \\
\hline ADHD & Attention deficit/hyperactivity disorder \\
\hline BT & Behavioural therapy \\
\hline Connors & ADHD Connors Test \\
\hline DSM-IV & $\begin{array}{l}\text { Diagnostic and Statistical Manual } \\
\text { of Mental Disorders 4th edn }\end{array}$ \\
\hline ICD-9/ICD-10 & $\begin{array}{l}\text { International Classification of Diseases } \\
\text { 9th and 10th Revision }\end{array}$ \\
\hline IOWA & $\begin{array}{l}\text { Inattention/Overactivity With } \\
\text { Aggression screening tool }\end{array}$ \\
\hline SNAP-IV & $\begin{array}{l}\text { Swanson, Nolan and Pelham IV } \\
\text { Rating Scale }\end{array}$ \\
\hline
\end{tabular}

\section{Introduction}

Attention deficit/hyperactivity disorder (ADHD) affects as many as 3 to $9 \%$ of children worldwide [15, 19] and is associated with significant and wide-ranging impairments. 
ADHD is one of the most common psychiatric disorders in childhood and is characterized by developmentally inappropriate levels of inattention, hyperactivity and/or impulsivity [2]. Children with ADHD struggle in the areas of academic functioning, self-esteem and interpersonal relationships [1, $13,14]$, and they are at higher risk for mental health comorbidities such as mood disorders and substance use disorders $[4,5,8,22]$. Studies have shown that families of children with ADHD experience considerable emotional and financial stressors [10, 12, 23], and ADHD has also been shown to negatively impact the health-related quality of life for both children and adults [9]. Taken together, these negative short- and long-term outcomes of ADHD on patients and families make it a public health concern and affirm the need for effective treatment [15].

According to European guidelines, the diagnosis and management of ADHD consists of nonpharmacological options, including behavioural therapy (BT), and pharmacological options, including stimulants (long- and shortacting methylphenidates and amphetamines) and nonstimulants $[15,24]$. However, the availability of and access to treatments vary across countries. Although much is known about the efficacy and safety of individual ADHD treatment options via randomized, controlled clinical trials, real-world treatment and utilization patterns of current ADHD therapies as well as physician practice patterns in the management of ADHD across European countries have not been studied extensively. Cultural beliefs and differences across countries contribute to the real-world variation regarding how ADHD is managed. To better understand current ADHD management in 'the real world' across Europe, it is important to understand how physicians in different countries diagnose and manage ADHD. It is also important to understand physician's perceptions on how currently available medications to treat ADHD are working to manage the condition. The purpose of this retrospective chart review was to descriptively illustrate variation in physician practice patterns in the management of ADHD in various Western European countries.

\section{Methods}

This study was designed as a retrospective review of patient medical records by their treating physicians (Fig. 1). In 2009, paediatricians, neuropaediatricians, child and/or adolescent psychiatrists and paediatric neurologists who treated patients with ADHD were identified from a database of healthcare providers in six countries in Western Europe: the UK, France, Germany, Italy, the Netherlands and Spain. Participating physicians were identified through the following sources: (a) physician directories maintained by local European medical associations and (b) local physician

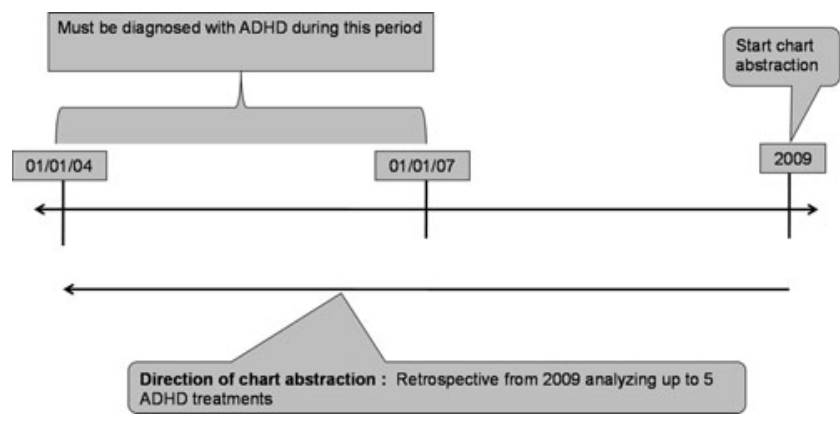

Fig. 1 Study design

telephone directories. Overall, no formal sampling procedure was employed for physician recruitment; however, physicians with ADHD expertise or prior positive working relationships with the fieldwork company were initially selected to be contacted for study participation.

Physicians were contacted by either email or phone calls to assess physician eligibility and interest in participating in the study. If eligible physicians indicated interest, they were directed to complete a web-based screening questionnaire. Physicians were screened as eligible for inclusion in the study if they were engaged in clinical practice for between 3 and 30 years, managed the treatment of at least five ADHD patients (aged 6-17 years) per month and were responsible for making ADHD treatment decisions.

Physicians were required to identify the most recent ADHD patients (up to a maximum of five patients aged 617 years) that they had seen at the time of the review. In order for patients to be included in the study, they should have had a documented diagnosis of ADHD between January 2004 and June 2007 and have had at least 2 years of follow-up post-diagnosis. Patients were also required to have received either pharmacological treatment or BT following the ADHD diagnosis. Patient charts were excluded if there was evidence of enrolment in a randomized clinical trial. No other specific sampling strategies were employed.

Physicians abstracted patient chart data, entered the data into an electronic web-based form and then translated it into the local language. Instructions for completing the chart abstraction were provided on the web-based form. The data collection tool was designed in such a way that physicians were not able to skip any questions; however, if certain information was not available in the patients' chart, physicians could select a 'don't know' option. Wording for key questions regarding satisfaction, symptom control and adherence to the treatment regimen has been included in the Appendix. Each chart abstraction form was estimated to take 15 to $30 \mathrm{~min}$ to complete. All data gathered were de-identified and made completely anonymous. As no identifying patient information was collected, physicians did not have to obtain permission from patients before abstracting charts. Physicians were nominally compensated for their time. 
Variables for assessment

Both physician characteristics and patient characteristics were collected. The following patient characteristics were collected from the chart: age at diagnosis and at start of treatment, gender, ethnicity, insurance status, education level, reasons for seeking evaluation, comorbidities at diagnosis and the level of patient engagement and family involvement with the condition and its treatment on a tenpoint scale where 1 represents 'not engaged/involved at all' and 10 represents 'strongly engaged/involved'. Other ADHD-related information collected included ADHD diagnostic criteria utilized, ADHD treatment goals, ADHD symptom presentation and levels of impairment at the time of ADHD diagnosis on a ten-point scale where 1 represented 'no impairment' and 10 represented 'high level of impairment' (from 2004 to 2007). Also, treatment modalities were collected starting from the time of chart abstraction and going backwards up to five previous ADHD treatments. Data collected on treatment modalities included dose, prescription date and reason for changing dose and/or therapy. A switch from one treatment modality to another or a discontinuation of treatment was considered as new treatment. Dose changes for the same medication were not considered as new treatment. Data on treatments administered in other clinics or those that exceeded the last five treatments were not documented.

Data on adherence to current and previous ADHD treatments were also collected. Physicians were asked to report on the patient's ADHD symptom control ('completely', 'moderately', 'poorly' or 'not controlled') and their satisfaction level ('very satisfied', 'moderately satisfied', 'neither satisfied nor dissatisfied', 'moderately dissatisfied' or 'very dissatisfied') with treatment at time of chart abstraction.

\section{Variable transformations}

Associations between patient characteristics and outcomes were examined using a binary outcome definition for adherence, physician perception of symptom control and physician satisfaction (all with current therapy at time of review) to simplify the analysis and its interpretation. Physician-estimated adherence to treatment was defined as $>80 \%$ adherence during weekdays and $>50 \%$ adherence during weekends and holidays in accordance with the literature characterizing the medication possession ratio [20] and its use in assessing ADHD medication adherence [3]. The four levels of symptom control were dichotomized to 'completely controlled' vs 'moderately', 'poorly' or 'not controlled'. The five levels of physician satisfaction were dichotomized to 'very satisfied' vs 'moderately satisfied', 'neither satisfied nor dissatisfied', 'moderately dissatisfied' or 'very dissatisfied'.
Statistical analysis

All study variables were summarized descriptively. Continuous variables were summarized and expressed in mean values, medians, ranges and standard deviations. Categorical variables were summarized in the form of proportion and frequency distributions. Summary statistics are provided by country for physician, patient and treatment characteristics and for diagnosis criteria used.

The significance $(p<0.05)$ of the associations was tested using Fisher's exact or $t$-tests for dichotomous and continuous variables, respectively. Odds ratios were reported for dichotomous values and mean values were reported for continuous variables.

All data were analysed using statistical software (SAS Version 9, SAS Institute, Inc., Cary, NC, USA).

\section{Results}

Physician characteristics

\section{Physician demographics}

A total of 340 physicians reviewed and abstracted charts for 779 patients. On average, physicians were engaged in clinical practice for 15 years (range 3 to 30 years). Each physician managed approximately 20 patients aged 6 to 12 years and 15 patients aged 13 to 17 years. Medical specialties are listed in Table 1.

\section{Patient characteristics}

\section{Patient demographics}

Patient demographics are presented in Table 2. Patient mean (SD) age at diagnosis was 8.9 (2.6) years old, which was similar across countries. The mean (SD) patient age at the start of chart abstraction was 12.1 (2.6) years, with little variation across countries. The majority of the patients $(77.5 \%$ [604/779]) were male and Caucasian (85.8 \% [557/649]). In France, the ethnicity of the patient was not allowed to be reported; therefore, the ethnicity data are based on a sample of 649 instead of 779 patients. Approximately $49 \%$ (384/779) of patients had one to three comorbidities at the time of diagnosis (Fig. 2). The most commonly reported comorbidities were behavioural disorders (59.3\% [462/779]), learning disabilities (47.4\% [369/779]), anxiety (35.7 \% [278/779]), aggression (35.3\% [275/779]) and oppositional defiant disorder (34.3\% [267/779]).

\section{ADHD diagnosis}

Feedback from teachers at school was the most common reason for seeking ADHD evaluations (78.3\% [610/779]) across all countries. Challenges raised by parents/family 
Table 1 ADHD diagnostic criteria and scales utilized by specialty for each country (physicians could select more than one diagnostic criterion utilized at diagnosis)

\begin{tabular}{|c|c|c|c|c|c|c|c|c|}
\hline \multirow[t]{2}{*}{ Country } & \multirow[t]{2}{*}{ Specialty $(n)$} & \multirow[t]{2}{*}{ Patients $(n)$} & \multicolumn{6}{|c|}{ ADHD diagnostic criteria and scales, $n(\%)$} \\
\hline & & & DSM-IV & ICD-9/ICD-10 & SNAP-IV & Connors & IOWA & Other \\
\hline \multirow[t]{7}{*}{ France } & Paediatrician (1) & 5 & $5(100.0)$ & 0 & 0 & $5(100.0)$ & 0 & 0 \\
\hline & Neuropaediatrician (2) & 7 & $6(85.7)$ & $6(85.7)$ & $5(71.4)$ & $2(28.6)$ & 0 & 0 \\
\hline & Neuropsychiatrist (1) & 2 & $2(100)$ & 0 & 0 & 0 & 0 & 0 \\
\hline & Psychiatrist (26) & 60 & $39(65.0)$ & $31(51.7)$ & $7(11.7)$ & $25(41.7)$ & $1(1.7)$ & 0 \\
\hline & $\begin{array}{l}\text { Paediatric/adolescent } \\
\text { psychiatrist (18) }\end{array}$ & 53 & $35(66.0)$ & $26(49.1)$ & $1(1.9)$ & $31(58.5)$ & 0 & 0 \\
\hline & Neurologist (2) & 3 & $3(100)$ & 0 & 0 & $1(33.3)$ & 0 & 0 \\
\hline & Total $(50)$ & 130 & $90(69.2)$ & $63(48.5)$ & $13(10.0)$ & $64(49.2)$ & $1(0.8)$ & 0 \\
\hline \multirow[t]{5}{*}{ Germany } & Paediatrician (24) & 70 & $17(24.3)$ & $56(80.0)$ & $4(5.7)$ & $47(67.1)$ & $4(5.7)$ & 0 \\
\hline & Neuropaediatrician (9) & 26 & $6(23.1)$ & $25(96.2)$ & $1(3.8)$ & $22(84.6)$ & 0 & 0 \\
\hline & Psychiatrist (12) & 35 & $8(22.9)$ & $31(88.6)$ & $1(2.9)$ & $28(80.0)$ & 0 & 0 \\
\hline & $\begin{array}{l}\text { Paediatric/adolescent } \\
\text { psychiatrist (7) }\end{array}$ & 20 & 0 & $20(100.0)$ & $1(5.0)$ & $17(85.0)$ & $1(5.0)$ & 0 \\
\hline & Total (52) & 151 & $31(20.5)$ & $132(87.4)$ & $7(4.6)$ & $114(75.5)$ & $5(3.3)$ & 0 \\
\hline \multirow[t]{4}{*}{ Italy } & Paediatrician (28) & 56 & $41(73.2)$ & $20(35.7)$ & $11(19.6)$ & $18(32.1)$ & $3(5.4)$ & 0 \\
\hline & Neuropaediatrician (38) & 74 & $50(67.6)$ & $29(39.2)$ & $18(24.3)$ & $21(28.4)$ & $5(6.8)$ & 0 \\
\hline & Neuropsychiatrist (8) & 14 & $10(71.4)$ & $5(35.7)$ & 0 & $4(28.6)$ & 0 & 0 \\
\hline & Total (74) & 144 & $101(70.1)$ & $54(37.5)$ & $29(20.1)$ & $43(29.9)$ & $8(5.6)$ & 0 \\
\hline \multirow[t]{5}{*}{ Netherlands } & Paediatrician (30) & 37 & $29(78.4)$ & $2(5.4)$ & 0 & $9(24.3)$ & $1(2.7)$ & 0 \\
\hline & Neuropsychiatrist (1) & 1 & 0 & 0 & 0 & 0 & 0 & 0 \\
\hline & Psychiatrist (9) & 12 & $12(100.0)$ & 0 & 0 & $4(33.3)$ & 0 & 0 \\
\hline & $\begin{array}{l}\text { Paediatric/adolescent } \\
\text { psychiatrist (16) }\end{array}$ & 24 & $19(79.2)$ & $1(4.2)$ & $2(8.3)$ & $9(37.5)$ & 0 & 0 \\
\hline & Total (56) & 74 & $60(81.1)$ & $3(4.1)$ & $2(2.7)$ & $22(29.7)$ & $1(1.4)$ & 0 \\
\hline \multirow[t]{4}{*}{ Spain } & Paediatrician (21) & 60 & $50(83.3)$ & $14(23.3)$ & $16(26.7)$ & $13(21.7)$ & $5(8.3)$ & 0 \\
\hline & Psychiatrist (15) & 40 & $28(70.0)$ & $15(37.5)$ & $4(10.0)$ & $13(32.5)$ & $2(5.0)$ & 0 \\
\hline & $\begin{array}{l}\text { Paediatric/adolescent } \\
\text { psychiatrist (14) }\end{array}$ & 34 & $28(82.4)$ & $15(44.1)$ & $3(8.8)$ & $15(44.1)$ & $3(8.8)$ & 0 \\
\hline & Total (50) & 134 & $106(79.1)$ & $44(32.8)$ & $23(17.2)$ & $41(30.6)$ & $10(7.5)$ & 0 \\
\hline \multirow[t]{5}{*}{ UK } & Paediatrician (23) & 57 & $20(35.1)$ & $11(19.3)$ & 0 & $42(73.7)$ & $3(5.3)$ & $20(35.1)$ \\
\hline & Neuropaediatrician (2) & 6 & $3(50.0)$ & $6(100.0)$ & 0 & $6(100.0)$ & 0 & 0 \\
\hline & Psychiatrist (7) & 18 & 7 (38.9) & $11(61.1)$ & $4(22.2)$ & $6(33.3)$ & 0 & $9(50.0)$ \\
\hline & $\begin{array}{l}\text { Paediatric/adolescent } \\
\text { psychiatrist (26) }\end{array}$ & 65 & $16(24.6)$ & $37(56.9)$ & $2(3.1)$ & $47(72.3)$ & $1(1.5)$ & $9(13.8)$ \\
\hline & Total (58) & 146 & $46(31.5)$ & $65(44.5)$ & $6(4.1)$ & $101(69.2)$ & $4(2.7)$ & $38(26.0)$ \\
\hline Total EU & & 779 & $434(55.7)$ & $361(46.3)$ & $80(10.3)$ & $385(49.4)$ & $29(3.7)$ & $38(4.9)$ \\
\hline
\end{tabular}

$n$ number of physician responses, $A D H D$ attention deficit/hyperactivity disorder, DSM-IV Diagnostic and Statistical Manual of Mental Disorders, 4th edn, ICD-9/ICD-10 International Classification of Diseases, Revision 9 or Revision 10, SNAP-IV Swanson, Nolan and Pelham Rating Scale, Version IV, Connors ADHD Connors Test, IOWA Inattention/Overactivity With Aggression screening tool

were also a common reason for seeking evaluation among $63.8 \%(497 / 779)$.

Across all countries, the commonly used diagnostic criteria included the Diagnostic and Statistical Manual of Mental Disorders, 4th edition (DSM-IV) (55.7 \% [434/779]), and International Classification of Diseases, Revision 9 or 10 (ICD-9/ICD-10) (46.3\% [361/779]). ADHD Connors Test (49.4\% [385/779]) was also commonly used, though physicians may have used more than one set of diagnostic criteria to make an ADHD diagnosis. As presented in Table 1, within each country the diagnostic criteria utilized varied based on physician specialty.

\section{ADHD symptoms and impairment levels at diagnosis}

The most common symptoms at diagnosis were the core symptoms of ADHD (inattention, impulsivity and hyperactivity) as well as impairments with school performance (Fig. 3). 
Table 2 Demographics for patients aged 17 years and younger

\begin{tabular}{|c|c|c|c|c|c|c|c|}
\hline & France & Germany & Italy & Netherlands & Spain & UK & Total (Europe) \\
\hline Number of patients & 130 & 151 & 144 & 74 & 134 & 146 & 779 \\
\hline \multicolumn{8}{|l|}{ Gender, $n(\%)$} \\
\hline Male & $111(85.4)$ & $113(74.8)$ & $108(75.0)$ & $57(77.0)$ & $97(72.4)$ & $118(80.8)$ & $604(77.5)$ \\
\hline Female & 19 (14.6) & $38(25.2)$ & $36(25.0)$ & $17(23.0)$ & $37(27.6)$ & $28(19.2)$ & $175(22.5)$ \\
\hline \multicolumn{8}{|c|}{ Age at ADHD diagnosis } \\
\hline Mean (SD) & $9.1(2.5)$ & $8.4(2.1)$ & $8.7(2.9)$ & $8.6(2.6)$ & $9.0(2.3)$ & $9.3(2.8)$ & $8.9(2.6)$ \\
\hline Median & 9 & 8 & 8 & 9 & 9 & 9 & 9 \\
\hline Range (min, $\max$ ) & 3,14 & 2,15 & 4,14 & 4,15 & 3,15 & 4,15 & 2,15 \\
\hline \multicolumn{8}{|c|}{ Age at chart abstraction } \\
\hline Mean (SD) & $12.4(2.6)$ & $11.8(2.3)$ & $11.8(2.8)$ & $11.7(2.5)$ & $12.1(2.5)$ & $12.7(2.7)$ & $12.1(2.6)$ \\
\hline Median & 12 & 12 & 11 & 12 & 12 & 13 & 12 \\
\hline Range (min, max) & 6,17 & 6,17 & 7,17 & 7,17 & 7,17 & 6,17 & 6,17 \\
\hline \multicolumn{8}{|c|}{ Patient currently in school, $n(\%)$} \\
\hline Yes & $109(83.8)$ & $144(95.4)$ & $135(93.8)$ & $72(97.3)$ & $123(91.8)$ & $126(86.3)$ & $709(91.0)$ \\
\hline No & $15(11.5)$ & $5(3.3)$ & $9(6.3)$ & $2(2.7)$ & $10(7.5)$ & $16(11.0)$ & $57(7.3)$ \\
\hline Don't know & $6(4.6)$ & $2(1.3)$ & $0(0.0)$ & $0(0.0)$ & $1(0.7)$ & $4(2.7)$ & $13(1.7)$ \\
\hline \multicolumn{8}{|c|}{ Private health insurance, $n(\%)$} \\
\hline Yes & $85(65.4)$ & $22(14.6)$ & $8(5.6)$ & $74(100)$ & $20(14.9)$ & $4(2.7)$ & $213(27.3)$ \\
\hline No & $24(18.5)$ & $129(85.4)$ & $99(68.8)$ & $0(0.0)$ & $90(67.2)$ & $136(93.2)$ & $478(61.4)$ \\
\hline Don't know & $21(16.2)$ & $0(0.0)$ & $37(25.7)$ & $0(0.0)$ & $24(17.9)$ & $6(4.1)$ & $88(11.3)$ \\
\hline
\end{tabular}

$S D$ standard deviation, $\min$ minimum, $\max$ maximum, $A D H D$ attention deficit/hyperactivity disorder

Approximately $44 \%(339 / 779)$ of patients were reported as having all three core symptoms at the time of diagnosis (Fig. 3). Furthermore, the majority of patients (63.7\% [496/779]) had three or more additional symptoms at diagnosis. More than a third of the patients exhibited anger, irritability and inappropriate behaviours. At the time of diagnosis, most physicians reported the level of impairment in inattention $(67.9 \%$ [529/779]), impulsivity (53.0\% [413/779]), hyperactivity (57.3\% [446/779]) and challenges in school (66.1\% $[515 / 779])$ as 8 or above on a ten-point scale. Most patients showed evidence of impairment both at school $(91.1 \%$ [710/779]) and at home (81.4\% [634/779]).

\section{ADHD treatment}

\section{ADHD treatment goals}

At diagnosis, most physicians across all six countries indicated (based on the provided choices) that a goal of ADHD treatment was to improve attention and functioning at school or work for
Fig. 2 Number and type of comorbidities at time of ADHD diagnosis, all countries $(n=779)$. Note that physicians can select more than one comorbidity at diagnosis

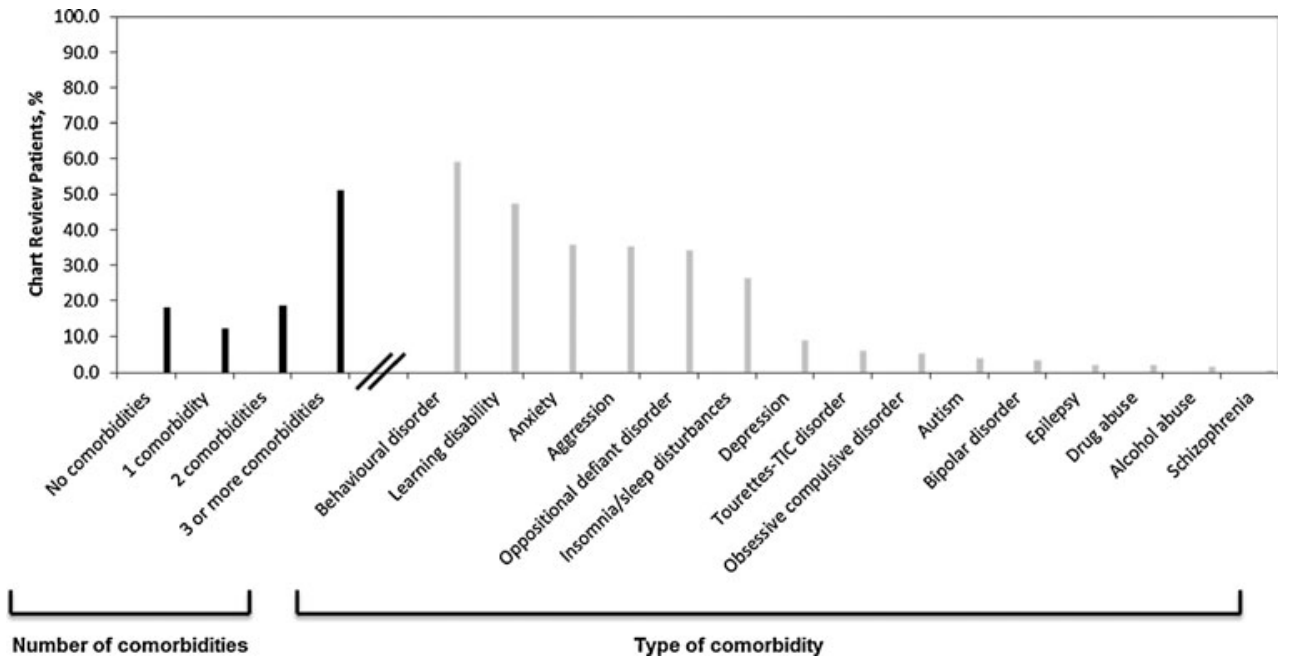


Fig. 3 Symptoms and impairment levels at diagnosis, all countries $(n=779)$. Note that physicians can select more than one symptom or impairment at diagnosis. Horizontal bars and data reflect the mean level of impairment for that symptom at diagnosis

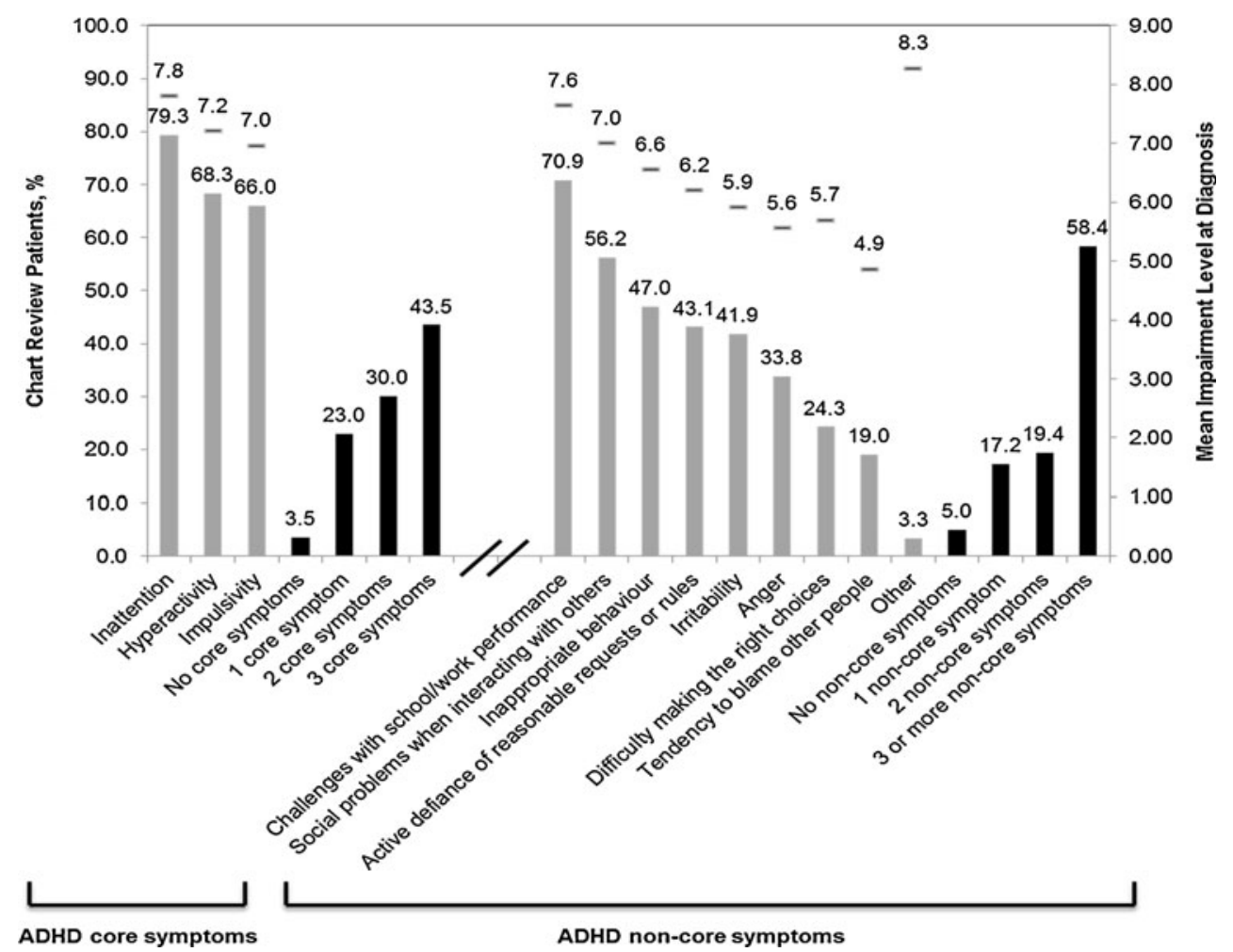

their patients (78.1 \% [609/779]; Fig. 4). Additional therapeutic goals were strongly aligned with controlling the other core ADHD symptoms of hyperactivity (60.3\% [470/779]) and impulsivity (60.5\% [471/779]). Overall, the physicians stated that they wanted control of all three core symptoms for
$38.1 \%(297 / 779)$ of their patients. Apart from core symptomrelated goals, the next most commonly indicated goals of treatment were to improve behaviour (62.0\% [483/779]), family relationships (51.4\% [400/779]) and relationship building (42.5\% [331/779]).
Fig. 4 Therapeutic goals of ADHD treatment at the time of diagnosis for chart review patients $(>1 \%)$, all countries $(n=779)$. Note that physicians can select more than one therapeutic goal of ADHD treatment at time of diagnosis

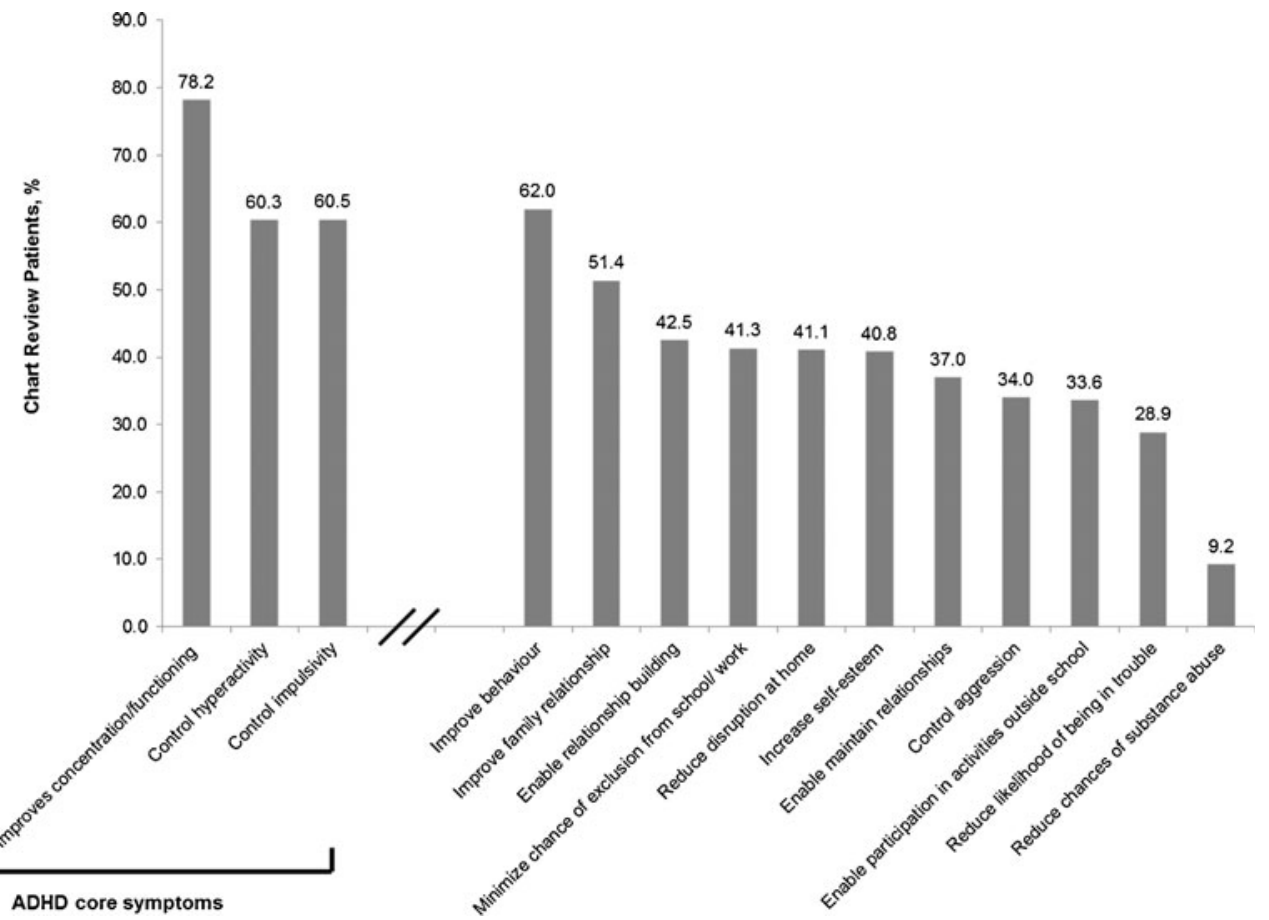




\section{ADHD treatments utilized and treatment patterns}

At the time of chart abstraction, $49.6 \%(386 / 779)$ were on their first ADHD treatment regimen (either drug or nondrug), $37.9 \%(295 / 779)$ had one previous line of therapy and the remaining $12.6 \%(98 / 779)$ of patients received two or more previous lines of therapy (Table 3). Germany had the most number of patients with three or more total lines of therapy (19.9\% [29/151]). Approximately $80 \%$ of patients had $\leq 0.5$ years between ADHD diagnosis and the initiation of treatment.

Overall, $34.5 \%(269 / 779)$ were treated with a combination of pharmacotherapy and BT, whereas $48.0 \%$ (374/779) of patients were undergoing treatment with pharmacotherapy only and $11.6 \%(90 / 779)$ with BT only (Table 3$)$. A small percentage of patients (5.9\% [46/779]) did not receive any treatment at the time chart abstraction was completed.

Across all countries, excluding Italy where long-acting methylphenidates are not approved for use, long-acting methylphenidate was the predominant treatment choice (among $55.8 \%$ of patients) either as monotherapy or in combination. Overall, short-acting methylphenidates ( $25.1 \%$ of patients) and atomoxetine (13.5\% of patients) were the next most commonly used treatments (Table 3 ).

Association between key predictor variables and outcomes

Overall, $71.4 \%$ of patients with ADHD were estimated by physicians to have high rates of adherence ( $>80 \%$ weekdays and $>50 \%$ weekends). Adherence was estimated to be highest in patients receiving combination medication therapy $(80.0 \%)$ and lowest for patients receiving BT only (12.2\%). However, according to physician judgement, only $30.8 \%$ of patients showed 'complete symptom control'. Symptom control was highest for patients receiving long-acting methylphenidate $(36.2 \%)$ and lowest for patients receiving BT only (15.6\%). Only $31.8 \%$ of physicians were 'very satisfied' with their patients' ADHD treatment at the time of chart abstraction. Highest physician satisfaction was reported for patients receiving medication combination therapy (38.8\%) and lowest satisfaction was reported for patients receiving BT only (14.4\%).

Table 3 ADHD treatment utilization and patterns

\begin{tabular}{|c|c|c|c|c|c|c|c|c|c|c|c|c|c|c|}
\hline & \multicolumn{2}{|c|}{ France } & \multicolumn{2}{|c|}{ Germany } & \multicolumn{2}{|c|}{ Italy } & \multicolumn{2}{|c|}{ Netherlands } & \multicolumn{2}{|c|}{ Spain } & \multicolumn{2}{|l|}{ UK } & \multicolumn{2}{|c|}{ Total (Europe) } \\
\hline & $N$ & $\%$ & $N$ & $\%$ & $N$ & $\%$ & $N$ & $\%$ & $N$ & $\%$ & $N$ & $\%$ & $N$ & $\%$ \\
\hline Total number of patients $(N)$ & \multicolumn{2}{|c|}{130} & \multicolumn{2}{|c|}{151} & \multicolumn{2}{|c|}{144} & \multicolumn{2}{|r|}{74} & \multicolumn{2}{|c|}{134} & \multicolumn{2}{|c|}{146} & \multicolumn{2}{|r|}{779} \\
\hline \multicolumn{15}{|l|}{ Lines of treatment } \\
\hline One & 85 & 65.4 & 77 & 51.0 & 81 & 56.3 & 46 & 62.2 & 69 & 51.5 & 64 & 43.8 & 386 & 49.6 \\
\hline Two & 37 & 28.5 & 45 & 29.8 & 60 & 41.7 & 19 & 25.7 & 48 & 35.8 & 55 & 37.7 & 295 & 37.9 \\
\hline Three & 7 & 5.4 & 24 & 15.9 & 3 & 2.1 & 7 & 9.5 & 15 & 11.2 & 17 & 11.6 & 73 & 9.4 \\
\hline Four & 1 & 0.8 & 3 & 2.0 & 0 & 0.0 & 1 & 1.4 & 1 & 0.8 & 7 & 4.8 & 18 & 2.3 \\
\hline Five or more & 0 & 0.0 & 2 & 1.3 & 0 & 0.0 & 1 & 1.4 & 1 & 0.8 & 3 & 2.1 & 7 & 0.90 \\
\hline \multicolumn{15}{|l|}{ Current treatment type $\mathrm{e}^{\mathrm{a}}$} \\
\hline No treatment ${ }^{\mathrm{b}}$ & 12 & 9.2 & 14 & 9.37 & 9 & 6.3 & 2 & 2.7 & 2 & 1.5 & 7 & 4.8 & 46 & 5.9 \\
\hline Pharmacotherapy only & 71 & 54.2 & 84 & 55.6 & 33 & 22.9 & 45 & 60.8 & 48 & 35.8 & 93 & 63.7 & 374 & 48.0 \\
\hline BT only & 10 & 7.7 & 10 & 6.6 & 59 & 41.0 & 1 & 1.4 & 9 & 6.7 & 1 & 0.9 & 90 & 11.6 \\
\hline Pharmacotherapy and BT & 37 & 28.5 & 43 & 28.5 & 43 & 29.9 & 26 & 35.1 & 75 & 56.0 & 45 & 30.8 & 269 & 34.5 \\
\hline \multicolumn{15}{|l|}{ Current treatment class ${ }^{\mathrm{c}, \mathrm{d}}$} \\
\hline Short-acting MPH & 39 & 34.2 & 56 & 36.8 & 43 & 54.4 & 25 & 31.7 & 0 & 0.0 & 16 & 10.2 & 179 & 25.1 \\
\hline Long-acting $\mathrm{MPH}^{\mathrm{e}}$ & 73 & 64.0 & 82 & 54.0 & 0 & 0.0 & 45 & 57.0 & 91 & 68.9 & 107 & 68.2 & 398 & 55.8 \\
\hline Short-acting AMP & 0 & 0.0 & 1 & 0.76 & 7 & 8.9 & 1 & 1.3 & 0 & 0.0 & 2 & 1.3 & 11 & 1.5 \\
\hline Atomoxetine $^{\mathrm{f}}$ & 1 & 0.9 & 13 & 8.6 & 29 & 36.7 & 8 & 10.1 & 13 & 9.9 & 32 & 20.4 & 96 & 13.5 \\
\hline Others & 1 & 0.9 & 0 & 0.0 & 0 & 0.0 & 0 & 0.0 & 28 & 21.2 & 0 & 0.0 & 29 & 4.1 \\
\hline
\end{tabular}

$N$ total number of patients, $B T$ behavioural therapy, $M P H$ methylphenidate, $A M P$ amphetamine

${ }^{a}$ Percentages are based on the total number of patients reporting treatment type

${ }^{\mathrm{b}}$ Not included in any analyses

${ }^{\mathrm{c}}$ Percentages are based on the total number of patients reporting treatment class

${ }^{\mathrm{d}}$ Treatment could be monotherapy or combination therapy

${ }^{\mathrm{e}}$ Long-acting MPH is not approved for use in Italy

${ }^{\mathrm{f}}$ Atomoxetine is not approved for use in France 
Generally, we found positive associations between the need to improve inattention as a treatment goal at diagnosis, increased patient engagement and increased family involvement and all three outcomes (adherence, symptom control and physician satisfaction with treatment). The odds of a favourable outcome for patients with improving inattention as a treatment goal were approximately twofold higher than for those patients for whom improving inattention was not a stated goal $(\mathrm{OR}=2.1 ; 95 \% \mathrm{CI}=1.5-3.1 ; p<0.0001$; Table 4$)$. Similarly, improved mean scores for patient engagement and family involvement were positively associated with adherence, symptom control and physician satisfaction. For example, adherent patients had a mean engagement score of 6.7 versus 5.7 for nonadherent patients (Table 4).

Alternatively, increased comorbidities at diagnosis (both total number and specific types) were negatively associated with outcomes. For instance, in patients with comorbid Tourette syndrome, the odds of favourable symptom control and physician satisfaction were reduced fivefold $(\mathrm{OR}=0.2$; $95 \% \mathrm{CI}=0.1-0.5 ; p<0.0001)$ and 3.3 -fold $(\mathrm{OR}=0.3 ; 95 \%$ $\mathrm{CI}=0.1-0.6 ; 0.0001 \leq p<0.001)$, respectively. Patients perceived to have complete symptom control had a mean number of 2.2 comorbidities compared to a mean number of 3.0 comorbidities in those patients without complete symptom control $(p<0.0001$; Table 4$)$.

The presence of certain ADHD symptoms at the time of diagnosis was also associated with unfavourable outcomes. The odds of favourable physician satisfaction with ADHD treatment was reduced 1.7-fold in patients with the symptom of anger at the time of diagnosis $(\mathrm{OR}=0.6 ; 95 \% \mathrm{CI}=0.4$ $0.8 ; 0.0001 \leq p<0.001)$. Furthermore, as seen in Table 4, there were multiple impairments at the time of diagnosis that were negatively associated with adherence, symptom control and physician satisfaction. For example, patients whose symptoms were completely controlled demonstrated a mean 'active defiance' impairment score of 5.6 compared with a score of 6.5 in those who did not demonstrate complete symptom control $(p<0.0001)$.

\section{Country differences}

Patient comorbidities at the time of ADHD diagnosis varied considerably across countries. The majority of countries reported at least one patient with each comorbidity represented in Fig. 2; however, data from Germany did not include any patients with schizophrenia, obsessive compulsive disorder, alcohol abuse, epilepsy or drug abuse; the Netherlands did not report any patients with bipolar disorder, schizophrenia or alcohol abuse; and Spain and the UK did not report any patients with schizophrenia. Also, patient membership to private insurance differed based on country. One hundred percent of patients from the Netherlands had private insurance compared with just $2.7 \%$ of patients from the UK.
The diagnostic criteria used by the treating physicians varied based on country. The DSM-IV criteria for diagnosing ADHD were most commonly used in France $(69.2 \%$ [90/130]), Italy $(70.1 \%[101 / 144])$, the Netherlands $(81.1 \%$ [60/74]) and Spain (79.1 \% [106/134]). ADHD Connors Test was frequently part of the diagnostic assessment in the UK (69.2\% [101/146]). ICD-9/ICD-10 diagnostic criteria were most commonly used in Germany (87.4 \% [132/151]).

Country level variation in the treatment of ADHD was also noted. The UK had the highest rate of treatment with pharmacotherapy alone at $63.7 \%(93 / 146)$. Treatment with BT alone was most common in Italy (41 \% [59/144]) and least common in the UK $(<1 \%[1 / 146])$. More than $54 \%$ of patients in Italy used short-acting methylphenidates, while Spain did not report any use at all. Atomoxetine was most commonly used in Italy $(36.7 \%)$, but it was not available in France because it has not been approved by the Comité Economique des Produits de Santé. Short-acting amphetamines were not used in France or Spain and were used by less than $2 \%$ of patients in Germany, the UK and the Netherlands. The highest use for short-acting amphetamines is in Italy (9\%) (Table 3 ).

The percentage of patients who adhered to their ADHD treatment ranged from $50.8 \%(62 / 122)$ in Italy to $80.3 \%$ (94/117) in France. Physicians from the Netherlands reported the highest percentages of 'complete symptom control' $(52.8 \%$ [38/72]), while Italian physicians reported the lowest percentage (16.4\% [22/134]). Methylphenidate 'very good responders' ranged from $11.1 \%(16 / 144)$ in Italy to $35.1 \%$ $(53 / 151)$ in Germany. Physicians in Germany (46.0\% [63/137]) and the Netherlands (59.7\% [43/72]) reported the highest percentages of 'very satisfied', while physicians in Italy reported the lowest percentage (14.8\% [20/135]).

\section{Discussion}

Country-level variations were evident in patient characteristics as well as ADHD diagnosis, treatment and outcomes. Patients had differences in comorbidities at the time of ADHD diagnosis across countries. Therefore, it is important that all treating physicians have a similar knowledge and understanding not only of the diagnosis and management of ADHD but also the associated comorbid conditions to deliver optimal treatment based on individual patient needs and a global view of the problems. Evaluations of differences in treatment based on patient comorbidities are planned for future analyses.

Patients also had differences in private insurance membership based on country. In the Netherlands, all patients were members of private insurance, but in the UK, where ADHD treatment is free under the National Health Service, only $2.7 \%$ had private insurance. The discrepancies in membership to private insurance across countries may influence ADHD management and treatment decisions for patients. Future analyses 


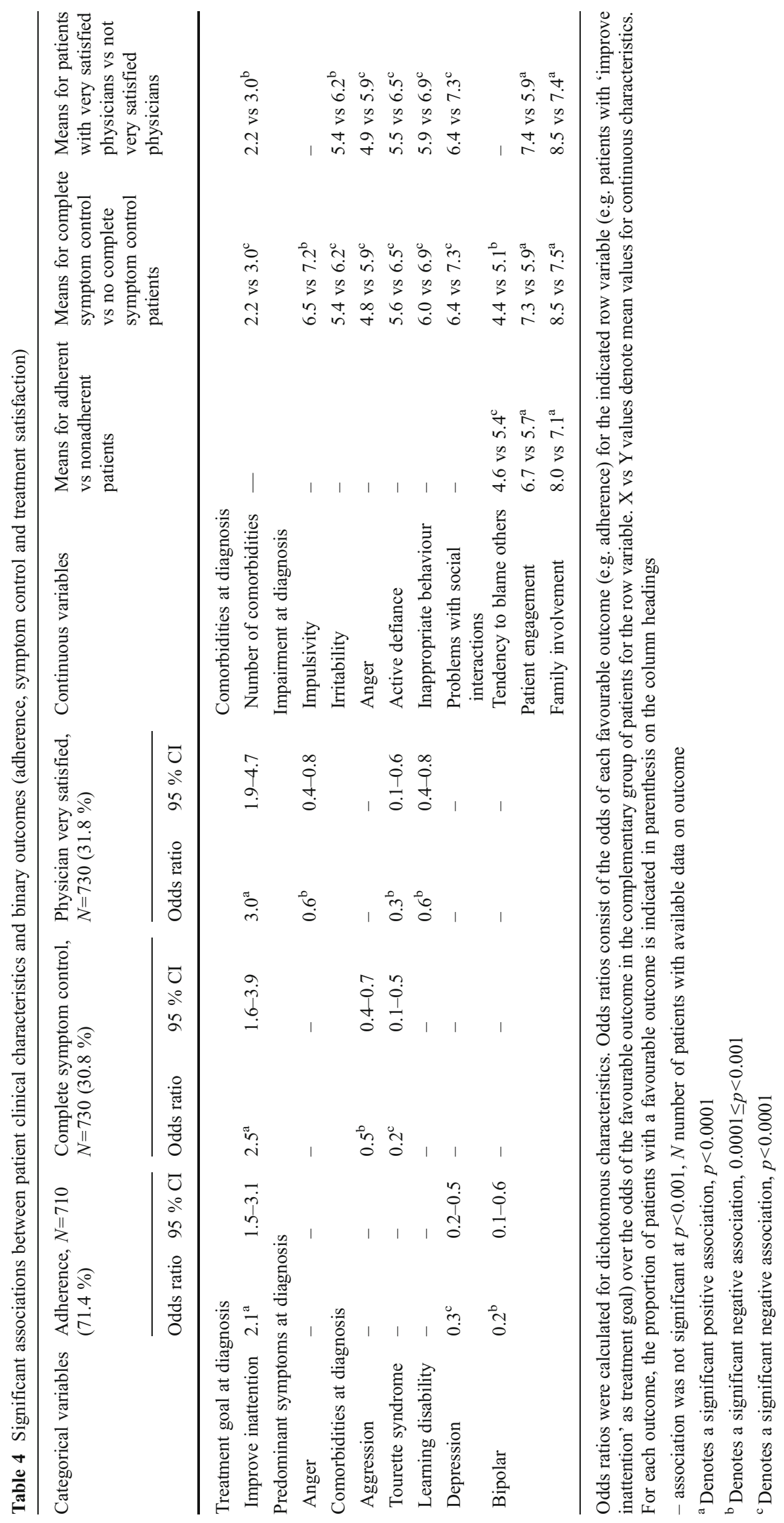


are planned to better understand ADHD management differences within countries and specialties as well as differences in treatment based on comorbidities.

Within each country, the criteria used to diagnose ADHD varied by physician specialty as well. The criteria provided in DSM-IV were the most commonly used to diagnose ADHD in the countries studied. Use of the Swanson, Nolan and Pelham IV Rating Scale (SNAP) and the Inattention/ Overactivity With Aggression (IOWA) screening tool increased each year from 2004 to 2007. Although scales like SNAP and IOWA are valuable for screening patients for ADHD, if used alone, they may lead to overdiagnosis or misdiagnosis. Adoption of standardized diagnostic criteria across countries may address some of the variability noted worldwide in ADHD prevalence [15, 19]. ADHD diagnosis and management differences within countries and within physician specialties are planned for future analyses.

At ADHD diagnosis, physicians regarded core ADHD symptom control as a primary therapeutic goal. In the short term, controlling core symptoms is of key importance as hyperactivity, impulsivity and inattention frequently create dysfunction for patients, their families and their peers. However, it is important to note that ADHD treatment is not limited to symptom control only. Treatment goals must also include longer-term objectives such as improving the quality of life for both the patient and their families and reducing functional impairment for the patient [18].

In this study of ADHD treatment in European countries, more than half of patients received long-acting methylphenidate as the treatment of choice, except in Italy where it was not approved and therefore short-acting methylphenidates were the treatment of choice. This may also account for a higher rate of BT only and a lower rate of treatment response and treatment satisfaction in Italy compared with other countries. Whether or not BT was available through national health plans and consideration of waiting times may have affected these numbers. In addition, differing recommendations from the various physician specialties and other variations in availability of medication may have also influenced these data. The rationale behind the choices of ADHD treatments (i.e. symptom severity, comorbidity, etc.) is planned for further analysis.

Overall, across all of the countries studied, patients with ADHD were considered by physicians to have high rates of adherence ( $>80 \%$ weekdays, $>50 \%$ weekends) with treatment on school or working days. However, less than one third of the patients were perceived by their physicians to exhibit 'complete symptom control' and less than one third of physicians were 'very satisfied' with the current ADHD treatment for their patients. The low overall percentages and high country variability for 'complete symptom control' and 'very satisfied' may be indicative of cultural differences among countries in the acceptability of physicians indicating dissatisfaction with ADHD therapy or as a result of inconsistency among countries in shared decision-making between physicians and patients/caregivers. We observed that patient/family involvement in the disorder and its treatment was positively associated with adherence, symptom control and physician satisfaction with treatment, reflecting the influence on treatment outcomes of shared decision-making [25]. In addition, low symptom control and satisfaction may be influenced by the lack of optimal treatment. In this study, whether or not titration of medication was optimal was not possible to ascertain. Clearly, physicians should endeavour to optimize management with pharmacological and nonpharmacological treatments currently available. Treatment should be individualized for each patient to ensure optimal response. However, this lack of symptom control and physician satisfaction with currently available treatment suggests that there also remains an unmet need in the six European countries studied with regard to available ADHD treatment options. Patients may be partial responders or nonresponders to one medication for ADHD, but that is not predictive of response to another class of medications [17, 18, 20]. Therefore, treatment optimization may include consideration of other ADHD medication classes not discussed herein, such as long-acting amphetamines [6, 26], alpha-2 agonists [7, 11, 16, 21] or ongoing BT. Management of coexisting conditions is also vital to improve overall outcomes, which was not possible to assess in this study.

\section{Limitations}

This study was a retrospective chart review with inherent study design limitations, including the potential for incomplete or missing documentation as well as the inability to establish causality. The potential for selection bias in this study should be considered due to the convenience sampling strategy implemented. It is not known whether a greater number of physicians participated from secondary referral centres compared with those from primary care settings; thus, it is not possible to determine whether an oversampling of charts from more complex or difficult patients occurred in this study. Confounding factors included the variable availability of ADHD treatments, including BT, across countries and the lack of information regarding whether a patient started initial ADHD therapy in a clinic that was different from the clinic where the actual medical record abstraction occurred. Because this was an observational study of a convenience sample where patient charts were not sampled randomly, the generalizability of these study results to the entire European population may be limited. Furthermore, this study was conducted for descriptive and exploratory purposes and was not designed for testing of particular statistical hypotheses. As such, $p$-values presented in the results should be considered descriptive. However, given the fact that this is the first work that attempted to study real-world practice variation and management of ADHD across European countries, the 
evidence generated in this research still provides valuable additional information to the body of literature in ADHD.

\section{Conclusions}

ADHD management differs across European countries and across physician specialties. Variations in patient characteristics as well as ADHD diagnosis, treatment and outcomes were evident between countries. Although a high proportion of patients were reported to be adherent to currently available therapy in Europe, less than one third of physicians perceived patients as having complete ADHD symptom control and less than one third of physicians were satisfied with ADHD treatments for their patients. These results suggest that European patients may benefit from better standardization of ADHD management across countries and additional treatment options.

Acknowledgments Financial support for manuscript development was provided by Shire Development, LLC. The authors acknowledge that editorial assistance in the preparation of this manuscript was provided by Laura Miesle, PharmD, CMPP, of The JB Ashtin Group, Inc. The authors would also like to thank Pierre Pigeon and Valerie Derrien from $\mathrm{A}+\mathrm{A}$ Healthcare Research for providing assistance with fieldwork for this study.

Conflict of interest Dr. Hodgkins is an employee of Shire Pharmaceuticals, LLC. Ms. Mitra and Mr. Davis are employees of RTI Health Solutions and served as consultants to Shire Pharmaceuticals, LLC. Dr. Setyawan is an employee of Shire Pharmaceuticals, LLC. Dr Quintero has received research funding from Janssen, Lilly, Shire and the Spanish Health Ministry and has participated as a speaker with Lilly, Janssen, Tomas Pascual Foundation, and Shire. Dr. Shaw was an employee of Shire at the time of these analyses. Dr. Fridman is an employee of AMF Consulting, Inc., and served as a consultant to Shire. Dr. Harpin has received research funding from Shire, Eli Lilly and Flynn Pharma and has spoken at educational events sponsored by Shire, Eli Lilly, Janssen Cilag and Flynn Pharma.

Open Access This article is distributed under the terms of the Creative Commons Attribution License which permits any use, distribution, and reproduction in any medium, provided the original author(s) and the source are credited.

\section{Appendix}

Web-based chart abstraction form: key questions

Which of the following statements best describes the level of compliance of this patient with this treatment for each specific circumstance?

Single answer per column

\begin{tabular}{|c|c|c|c|}
\hline & $\begin{array}{l}\text { School/working } \\
\text { days }\end{array}$ & Weekends & Holidays \\
\hline $\begin{array}{l}\text { The patient follows } \\
\text { the treatment prescribed } \\
\text { more than } 80 \% \text { of the time }\end{array}$ & 1 & 1 & 1 \\
\hline $\begin{array}{l}\text { The patient follows } \\
\text { the treatment prescribed }\end{array}$ & 2 & 2 & 2 \\
\hline
\end{tabular}

between $51-80 \%$

of the time

The patient follows

the treatment prescribed

between $25-50 \%$

of the time

The patient follows

the treatment prescribed

less than $25 \%$ of the time

Not applicable / the treatment 5

is not prescribed for this

circumstance
Don't know
99
99

How well controlled are ADHD symptoms for this patient with this current treatment?

\section{Single answer}

$\begin{array}{ll}\text { Completely controlled } & 1 \\ \text { Moderately controlled } & 2 \\ \text { Poorly controlled } & 3 \\ \text { Not controlled at all } & 4 \\ \text { Don't know } & 99\end{array}$

How would you define your level of overall satisfaction with this current treatment?

Single answer

\begin{tabular}{ll}
\hline Very satisfied & 1 \\
Moderately satisfied & 2 \\
Neither satisfied or dissatisfied & 3 \\
Moderately dissatisfied & 4 \\
Very dissatisfied & 5 \\
\hline
\end{tabular}

\section{References}

1. Adesman AR (2001) The diagnosis and management of attentiondeficit/hyperactivity disorder in pediatric patients. Prim Care Companion J Clin Psychiatry 3:66-67

2. American Psychiatric Association (2000) Disorders usually first diagnosed in infancy, childhood, or adolescence. In: Diagnostic and statistical manual of mental disorders, 4th edn, text revision. American Psychiatric Association, Washington, DC, pp 85-93

3. Barner JC, Khoza S, Oladapo A (2011) ADHD medication use, adherence, persistence and cost among Texas Medicaid children. Curr Med Res Opin 27(Suppl 2):13-22

4. Biederman J (1998) Attention-deficit/hyperactivity disorder: a lifespan perspective. J Clin Psychiatry 59(Suppl 7):S4-S16

5. Biederman J, Faraone S, Milberger S, Guite J, Mick E, Chen L, Mennin D, Marrs A, Ouellette C, Moore P, Spencer T, Norman D, Wilens T, Kraus I, Perrin J (1996) A prospective 4-year follow-up study of attention-deficit hyperactivity and related disorders. Arch Gen Psychiatry 53:437-446

6. Biederman J, Krishnan S, Zhang Y, McGough JJ, Findling RL (2007) Efficacy and tolerability of lisdexamfetamine dimesylate (NRP-104) in children with attention-deficit/hyperactivity disorder: a phase III, multicenter, randomized, double-blind, forced-dose, parallel-group study. Clin Ther 29:450-463 
7. Biederman J, Melmed RD, Patel A, McBurnett K, Konow J, Lyne A, Scherer N, for the SPD503 Study Group (2008) A randomized, double-blind, placebo-controlled study of guanfacine extended release in children and adolescents with attention-deficit/hyperactivity disorder. Pediatrics 121(1):e73-e84

8. Biederman J, Newcorn J, Sprich S (1991) Comorbidity of attention deficit hyperactivity disorder with conduct, depressive, anxiety, and other disorders. Am J Psychiatry 148:564-577

9. Coghill D (2010) The impact of medications on quality of life in attention-deficit hyperactivity disorder. CNS Drugs 24(10):843-866

10. Harpin VA (2005) The effect of ADHD on the life of an individual, their family, and community from preschool to adult life. Arch Dis Child 90(Suppl 1):i2-i7

11. Jain R, Segal S, Kollins SH, Khayrallah M (2011) Clonidine extended-release tablets for pediatric patients with attentiondeficit/hyperactivity disorder. J Am Acad Child Adolesc Psychiatr 50(2):171-179

12. Johnston C, Mash EJ (2001) Families of children with attentiondeficit/hyperactivity disorder: review and recommendations for future research. Clin Child Fam Psychol Rev 4:183-207

13. Mannuzza S, Klein RG (2000) Long-term prognosis in attentiondeficit/hyperactivity disorder. Child Adolesc Psychiatr Clin North Am 9:711-726

14. Minde K, Lewin D, Weiss G, Lavigueur H, Douglas V, Sykes E (1971) The hyperactive child in elementary school: a 5 year, controlled, follow-up. Except Child 38:215-221

15. National Institute for Health and Clinical Excellence (2009) Attention deficit hyperactivity disorder: diagnosis and management of ADHD in children, young people and adults: national clinical practice guideline number 72 . National Institute for Health and Clinical Excellence, London

16. Palumbo DR, Sallee FR, Pelham WE, Bukstein OG, Daviss WB, McDermott MP, and the CAT Study Team (2008) Clonidine for attention-deficit/hyperactivity disorder treatment study: I. Efficacy and tolerability outcomes. J Am Acad Child Adolesc Psychiatry 47:180-187

17. Pliszka SR, Bernet W, Bukstein O, Walter HJ, Arnold V, Beitchman J, Benson RS, Chrisman A, Farchione T, Hamilton J, Keable H, Kinlan J, McClellan J, Rue D, Schoettle U, Shaw JA, Stock S, Ptakowski KK, Medicus J (2007) American Academy of Child and Adolescent Psychiatry work group on quality issues. Practice parameter for the assessment and treatment of children and adolescents with attention deficit-hyperactivity disorder. J Am Acad Child Adolesc Psychiatr 46:894-921

18. Pliszka SR, Crismon ML, Hughes CW, Pliszka SR, Crismon ML, Hughes CW, Conners CK, Emslie GJ, Jensen PS, McCraken JT, Swanson JM, Lopez M, the Texas Consensus Conference Panel on Pharmacotherapy of Childhood Attention-Deficit/Hyperactivity Disorder (2006) The Texas children's medication algorithm project: revision of the algorithm for pharmacotherapy of attention-deficit/ hyperactivity disorder. J Am Acad Child Adolesc Psychiatr 45:642657

19. Polanczyk G, de Lima MS, Horta BL, Biederman J, Rohde LA (2007) The worldwide prevalence of ADHD: a systematic review and metaregression analysis. Am J Psychiatry 164:942-948

20. Rizzo JA, Simons WR (1997) Variations in compliance among hypertensive patients by drug class: implications for health care costs. Clin Ther 19:1446-1457

21. Sallee FR, McGough J, Wigal T, Donahue J, Lyne A, Biederman J, for the SPD503 Study Group (2009) Guanfacine extended release in children and adolescents with attention-deficit/hyperactivity disorder: a placebo-controlled trial. J Am Acad Child Adolesc Psychiatry 48(2):155-165

22. Spencer TJ, Biederman J, Mick E (2007) Attention-deficit/hyperactivity disorder: diagnosis, lifespan, comorbidities, and neurobiology. J Pediatr Psychol 32:631-642

23. Swensen AR, Birnbaum HG, Secnik K, Marynchennko M, Greenberg P, Claxton A (2003) Attention-deficit/hyperactivity disorder: increased costs for patients and their families. J Am Acad Child Adolesc Psychiatr 42:1415-1423

24. Taylor E, Döpfner M, Sergeant J, Asherson P, Banaschewski T, Buitelaar J, Coghill D, Danckaerts M, Rothenberger A, SonugaBarke E, Steinhausen H-C, Zuddas A (2004) European clinical guidelines for hyperkinetic disorder-first upgrade. Eur Child Adolesc Psychiatr 13(Suppl 1):17-30

25. Toomey SL, Sox CM, Rusinak D, Finkelstein JA (2012) Why do children with ADHD discontinue their medication? Clin Pediatr 51:763-769

26. Wigal SB, Kollins SH, Childress AC, Squires L, for the 311 Study Group (2009) A 13-hour laboratory school study of lisdexamfetamine dimesylate in school-aged children with attention-deficit/ hyperactivity disorder. Child Adolesc Psychiatry Ment Health 3:17 